06

\title{
Таммовские состояния в брэгговских гетероструктурах на волноводно-щелевых линиях
}

\author{
(ㄱ Д.А. Усанов, ${ }^{1}$ С.А. Никитов, ${ }^{2}$ А.В. Скрипаль, ${ }^{1}$ Д.С. Рязанов ${ }^{1}$ \\ ${ }^{1}$ Саратовский национальный исследовательский государственный университет им. Н.Г. Чернышевского, \\ 410012 Саратов, Россия \\ ${ }^{2}$ Институт радиотехники и электроники им. В.А. Котельникова РАН, \\ 125009 Москва, Россия \\ e-mail: UsanovDA@info.sgu.ru
}

(Поступило в Редакцию 14 ноября 2017 г.)

Представлены результаты экспериментального исследования и расчета таммовских поверхностных состояний в брэгговской гетероструктуре, образованной из двух групп периодически расположенных отрезков волноводно-щелевой линии передачи, имеющих разные размеры. Установлено, что в „идеальной“ брэгговской гетероструктуре таммовские поверхностные состояния не возникают, таммовские поверхностные состояния возникают при наличии на границе двух брэгговских структур интерфейсного элемента с характеристиками, отличными от характеристик как одной, так и другой брэгговской структуры.

DOI: 10.21883/JTF.2018.07.46175.2561

Известно, что поверхностные электронные состояния Тамма появляются на границе полубесконечного кристалла и характеризуются дискретным энергетическим спектром и волновыми функциями, экспоненциально затухающими по мере удаления от поверхности в глубину кристалла и в пространство вне его [1-3]. В работах $[4,5]$ сообщалось о наблюдении локализованных поверхностных состояний (состояний Тамма) в сверхрешетке $\mathrm{AlGaAs} / \mathrm{GaAs}$, ограниченной слоем типа AlAs и AlGaAs. Авторы [6] исследовали таммовские состояния в сверхрешетках $\mathrm{AlGaAs} / \mathrm{GaAs}$ с измененной шириной последней (крайней) квантовой ямы. Результаты расчета таммовских состояний в полупроводниковых сверхрешетках с последней (крайней) квантовой ямой произвольной ширины и глубины приведены в работе [7].

В работе [8] было предложено расширенное определение таммовских состояний, как состояний, являющихся внутренними состояниями границы гетероперехода при наличии переходного (интерфейсного) слоя. Результаты расчета такого связанного таммовского состояния на границе сверхрешеток InAs/AlSb с переходными (интерфейсами) слоями типа InSb и AlAs приведены в работе [9].

При рассмотрении одномерных периодических структур, называемых одномерными фотонными кристаллами, установлено, что на границе фотонного кристалла возможна локализация электрического поля при контакте фотонного кристалла с однородным слоем, характеризующимся отрицательной диэлектрической проницаемостью (проводящая среда на частотах ниже плазменной) или отрицательной магнитной проницаемостью (магнитная среда на частоте в окрестности ферромагнитного резонанса). Такая локализация электрического поля трактуется как поверхностное таммовское состояние в фотонном кристалле. При этом на АЧХ фотонного кристалла, контактирующего с однородным сло- ем, наблюдается узкий пик коэффициента прохождения электромагнитной волны, связанный с возникновением таммовского состояния [10-12]. Возникновение локализованных таммовских состояний на краях фотонного кристалла, ограниченного пленкой нанокомпозита в виде нанопористого серебра, описано авторами [13].

Состояния Тамма могут также встречаться на границе двух соединенных фотонных кристаллов с различными размерами элементарных ячеек при перекрытии запрещенных зон этих двух кристаллов $[10,14]$. Существование таммовского поверхностного состояния на поверхности между двумя фотонными кристаллами экспериментально наблюдалось авторами [12,15].

В работе [12] исследовано соединение двух фотонных кристаллов оптического диапазона, в первом из которых слои $\mathrm{SiO}_{2}$ толщиной $138 \mathrm{~nm}$ чередовались со слоями $\mathrm{Ta}_{2} \mathrm{O}_{5}$, а во втором - со слоями Вi : YIG.

Идеальная стыковка этих фотонных кристаллов подразумевала наличие слоя $\mathrm{SiO}_{2}$ толщиной $138 \mathrm{~nm}$ между пленкой $\mathrm{Ta}_{2} \mathrm{O}_{5}$ и пленкой $\mathrm{Bi}:$ YIG на стыке двух фотонных кристаллов.

Такую структуру из двух фотонных кристаллов с идеальной стыковкой можно считать идеальной брэгговской гетероструктурой по аналогии с идеальным гетеропереходом, описываемым моделью Андерсона [16], который образуется между полупроводниками с абсолютно одинаковыми постоянными решетки.

Как следует из описания эксперимента [12], слой $\mathrm{SiO}_{2}$ в месте стыка двух фотонных кристаллов отсутствовал. Это следует трактовать как нарушение идеальности брэгговской гетероструктуры, которое и выполняло роль интерфейса между двумя фотонными кристаллами и обеспечивало возникновение оптического таммовского состояния на границе двух фотонных кристаллов, характеризующегося локализацией в области интерфейса 
пучности распределения электрического поля электромагнитной волны с максимальной напряженностью.

В работе [15] исследовано соединение двух микрополосковых СВЧ фотонных кристаллов, имеющих различные размеры элементарных ячеек, а именно имеются элементы с широкими и узкими верхними полосками микрополосковых линий передачи, длины элементов с широкими полосками различны в одном и другом фотонном кристаллах, а длины элементов с узкими полосками одинаковы. При теоретическом расчете и в эксперименте на границе двух фотонных кристаллов без нарушений включался элемент с узким полоском микрополосковой линии, длина которого отлична от длины элементов с узкими полосками, входящих в состав обоих фотонных кристаллов.

Этот элемент с узким полоском с измененной длиной создавал нарушение в брэгговской гетероструктуpe, составленной из двух фотонных кристаллов без нарушений, выполнял роль интерфейса и обеспечивал возникновение СВЧ-аналога таммовского состояния на границе двух фотонных кристаллов, характеризующегося локализацией в области интерфейса ярко выраженной пучности распределения электрического поля электромагнитной волны с максимальной напряженностью.

Таким образом, авторы работ, исследовавшие фотонные таммовские поверхностные состояния на границе двух соединенных фотонных кристаллов с различными размерами элементарных ячеек при перекрытии запрещенных зон этих двух кристаллов [10,14], фиксировали таммовские состояния в фотонных кристаллах как раз при наличии определенного интерфейсного элемента на границе двух фотонных кристаллов, выполняющего роль нарушения, не заостряя на этом внимания.

Можно утверждать, что предыдущие исследователи не рассмотрели случай отсутствия интерфейса на границе двух фотонных кристаллов и поэтому не смогли объяснить его роль в возникновении фотонных таммовских поверхностных состояний на границе двух соединенных фотонных кристаллов с различными размерами элементарных ячеек при перекрытии запрещенных зон этих двух кристаллов.

Таким образом, можно сделать вывод о том, что таммовские состояния возникают, когда нарушение периодичности является либо следствием полного отсутствия одной составляющей в элементе периодической структуры в месте стыка двух фотонных кристаллов, либо при наличии двух образующих элемент периодической структуры составляющих, следствием изменения в месте стыка параметров (например, его электрической длины) стыкуемой составляющей одного из кристаллов.

Как известно, отличительной особенностью фотонных кристаллов СВЧ диапазона является высокая технологичность их производства, макроскопичность элементов, составляющих их конструкцию, при этом в качестве периодически повторяющихся элементов СВЧ фотонного кристалла могут быть использованы отрезки различных типов линий передачи.

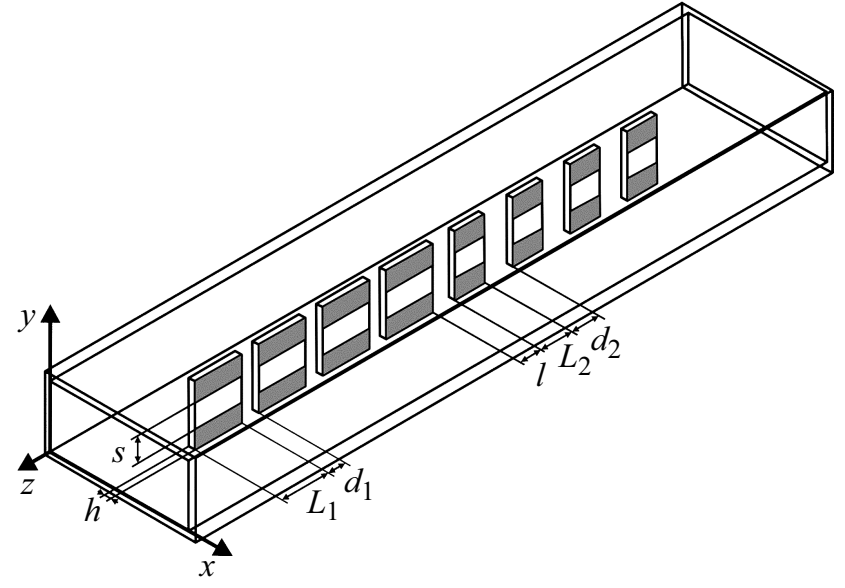

Рис. 1. Модель гетероструктуры, состоящей из двух брэгговских структур на основе волноводно-щелевых линий передачи, имеющих различные размеры элементарных ячеек. $L_{1,2}$ - длины отрезков волноводно-щелевой линии передачи; $d_{1,2}$ - длины регулярных отрезков волновода; $h$ - толщина подложки волноводно-щелевой линии, $s$ - ширина щели, $l$ - длина регулярного отрезка волновода (интерфейса). $L_{1}=13 \mathrm{~mm}, d_{1}=15 \mathrm{~mm}, L_{2}=15 \mathrm{~mm}, d_{2}=10 \mathrm{~mm}$, $s=4.0 \mathrm{~mm}, h=1.0 \mathrm{~mm}, \varepsilon=9.6$.

Настоящая работа посвящена исследованию особенностей возникновения фотонных таммовских поверхностных состояний на границе двух фотонных кристаллов без нарушений, выполненных в виде волноводнощелевых линий передачи, при наличии интерфейсного слоя на границе двух фотонных кристаллов.

Общий вид исследуемой брэгговской СВЧ структуры на основе волноводно-щелевых линий [17,18], составленной из двух подсистем, имеющих различные размеры элементарных ячеек, представлен на рис. 1. В центре поперечного сечения прямоугольного волновода $X$-диапазона $(22.86 \times 10.16 \mathrm{~mm})$ в $E$-плоскости размещались две группы периодически расположенных отрезков щелевой линии передачи, образующих в совокупности брэгговскую гетероструктуру.

Щелевая линия первой подсистемы брэгговской гетероструктуры выполнена на поликоровой $\left(\mathrm{Al}_{2} \mathrm{O}_{3}, \varepsilon=9.6\right)$ пластине длиной $L_{1}=15 \mathrm{~mm}$, шириной $10.16 \mathrm{~mm}$ и толщиной $1 \mathrm{~mm}$. На одну сторону пластины было нанесено золотое покрытие толщиной $0.01 \mathrm{~mm}$, ширина щели в покрытии составляла $s=4.0 \mathrm{~mm}$. Отрезки первой подсистемы волноводно-щелевой линии передачи разделялись отрезками регулярного волновода длиной $d_{1}=10 \mathrm{~mm}$. Длина отрезков волноводно-щелевой линии второй подсистемы брэгговской гетероструктуры составляла $L_{2}=13 \mathrm{~mm}$, а длина отрезков регулярного волновода $d_{2}=15 \mathrm{~mm}$. Каждая из подсистем брэгговской гетероструктуры состояла из четырех отрезков щелевой линии.

Численный расчет коэффициентов отражения и прохождения выполнялся с использованием программного обеспечения для трехмерного моделирования элек- 

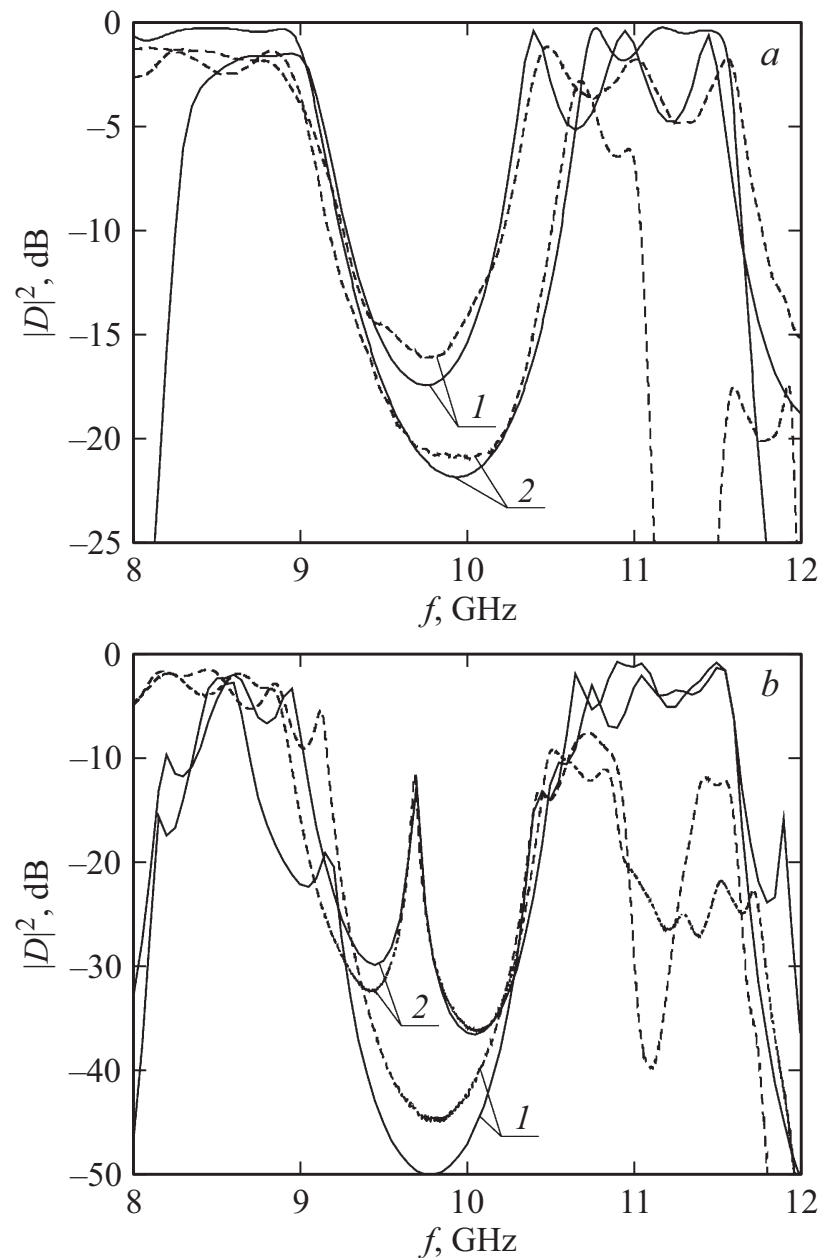

Рис. 2. Экспериментальные (штриховые кривые) и расчетные (сплошные кривые) частотные зависимости коэффициентов прохождения $|D|^{2}: a-$ для двух отдельных подсистем с размерами элементов: кривая $1-L_{1}=13 \mathrm{~mm}, d_{1}=15 \mathrm{~mm}$; кривая $2-L_{2}=15 \mathrm{~mm}, d_{2}=10 \mathrm{~mm} ; s=4.0 \mathrm{~mm}$, $h=1.0 \mathrm{~mm}, \varepsilon=9.6 ; b-$ для брэгговской гетероструктуры, составленной из двух последовательно соединенных брэгговских структур, состоящих из 4 отрезков волноводно-щелевой линии передачи, при различной длине интерфейсного слоя $l$ : $1-10,2-1 \mathrm{~mm}$.

тромагнитных полей методом конечных элементов ANSYS HFSS.

Частотные зависимости коэффициентов отражения и прохождения фотонной брэгговской гетероструктуры исследовались с помощью векторного анализатора цепей Agilent PNA-L Network Analyzer N5230A в диапазоне частот $8-12 \mathrm{GHz}$.

Длины отрезков волноводно-щелевой линии передачи и регулярных отрезков волновода каждой из двух брэгговских структур были выбраны таким образом, чтобы частоты, соответствующие серединам запрещенных зон одной и другой брэгговских структур, максимально совпадали. При этом вследствие различной ширины запрещенных зон этих структур наблю- далось лишь их частичное перекрытие в частотной области.

Спектры пропускания для каждой из двух подсистем брэгговской гетероструктуры в отдельности представлены на рис. 2, $a$.

Были измерены и рассчитаны АЧХ фотонной брэгговской гетероструктуры, составленной из двух последовательно соединенных брэгговских структур, имеющих различные размеры элементарных ячеек.

Как следует из результатов эксперимента и расчета, при длине $l$ регулярного отрезка волновода, соединяющего две брэгговские структуры и играющего роль интерфейсного слоя, равного длине регулярных отрезков
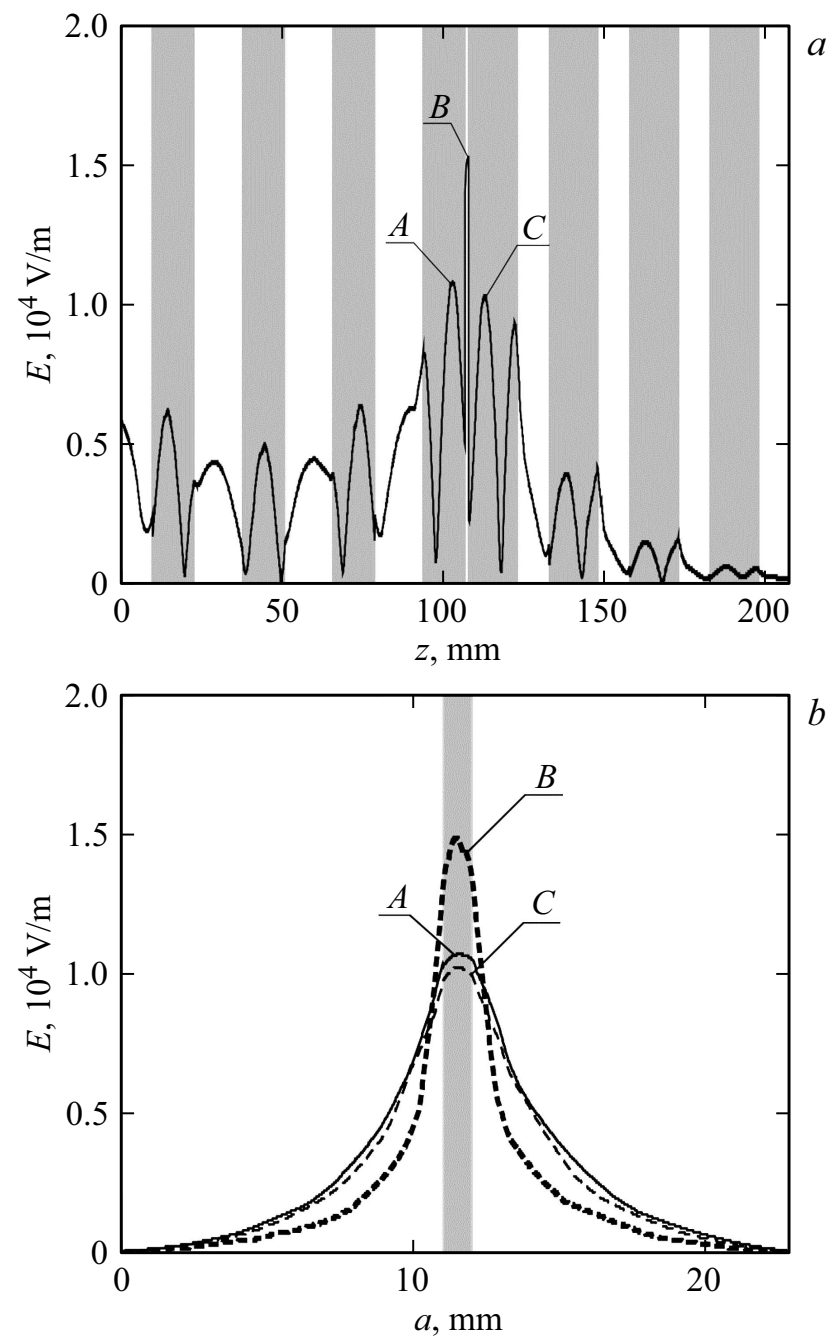

Рис. 3. Распределение напряженности электрического поля электромагнитной волны внутри брэгговской гетероструктуры на частоте, соответствующей пику коэффициента прохождения электромагнитной волны в запрещенной зоне: $a$ - вдоль направления распространения электромагнитной волны; $b-$ в плоскостях поперечного сечения волновода $(A$, $B, C)$ на рис. $3, a . f_{\text {Tamm }}=9.686 \mathrm{GHz}$. Темным цветом на рис. 3, a отмечены области, которые заняты отрезками волноводно-щелевой линии передачи, светлым обозначены области, занятые регулярными отрезками волновода. 
первой или второй брэгговской структур, АЧХ фотонной брэгговской гетероструктуры, которую можно называть „идеальной“ брэгговской структурой, характеризуется наличием запрещенной зоны с коэффициентом пропускания, достигающим $-45 \mathrm{~dB}$ (кривые 1 на рис. $2, b)$. При этом на АЧХ „идеальной“ брэгговской гетероструктуры в запрещенной зоне не наблюдался пик коэффициента прохождения электромагнитной волны, связанный с возникновением таммовского состояния.

При определенной длине $l$ интерфейсного слоя в запрещенной зоне фотонной брэгговской гетероструктуры, состоящей из двух последовательно соединенных брэгговских структур, возникал пик прохождения электромагнитной волны. Так, при длине $l$, равной $1 \mathrm{~mm}$, пик прохождения возникал в середине запрещенной зоны (кривые 2 на рис. $2, b$ ).

С целью выяснения особенностей локализации таммовских состояний на интерфейсной границе брэгговской гетероструктуры был выполнен расчет распределения напряженности электрического поля электромагнитной волны на частоте $f_{\text {Tamm }}$, соответствующей пику коэффициента прохождения электромагнитной волны в запрещенной зоне (рис. 2, b).

Результаты расчета напряженности электрического поля электромагнитной волны демонстрируют чередование узлов и пучностей внутри брэгговской гетероструктуры вдоль направления ее распространения (рис. $3, a$ ). При этом наблюдается локализованная на интерфейсной границе двух последовательно соединенных брэгговских структур пучность распределения электрического поля электромагнитной волны с максимальной напряженностью.

Анализ распределения поля в плоскостях поперечного сечения волновода, проходящих через пучности стоячей волны на отрезках волноводно-щелевой линии первой и второй последовательно соединенных брэгговских структур и через пучность на интерфейсной границе, свидетельствует о существенной локализации поля в середине широкой стенки волновода. При этом характер зависимости $E(x)$ существенно отличается от синусоидального, характерного для волны $H_{10}$ (рис. $3, b$ ).

Таким образом, экспериментально исследовано возникновение таммовских поверхностных состояний в фотонном кристалле, составленном из двух последовательно соединенных брэгговских структур, имеющих разные размеры элементарных ячеек и выполненных в виде волноводно-щелевых линий передачи. Сравнение результатов эксперимента и расчетных данных свидетельствует об их хорошем количественном совпадении.

Установлено, что в „идеальной“ брэгговской гетероструктуре таммовские поверхностные состояния не возникают. Таммовские поверхностные состояния на границе двух брэгговских структур возникают лишь при наличии на этой границе интерфейсного элемента с характеристиками, отличными от характеристик как одной, так и другой брэгговской структуры.
Работа выполнена при финансовой поддержке Министерства образования и науки РФ (государственное задание № 8.7628.2017/8.9).

\section{Список литературы}

[1] Tamm I.E. // Phys. Z. Sowiet Union. 1932. Vol. 1. P. 733-735.

[2] Tamm I.E. // Zh. Eksp. Teor. Fiz. 1932. Vol. 76. N 11-12. P. 849-850.

[3] Тамм И.Е. // ЖЭТФ. 1933. Т. 3. С. 34-43.

[4] Ohno H., Mendez E.E., Brum J.A., Hong J.M., AgulloRueda F., Chang L.L., Esaki L. // Phys. Rev. Lett. 1990. Vol. 64. N 21. P. 2555-2558.

[5] Ohno H., Mendez E.E., Alexandrou A., Hong J.M. // Surf. Sci. 1992. Vol. 267. P. 161-165.

[6] Agullo-Rueda F., Mendez E.E., Qhno H., Hong J.M. // Phys. Rev. B. 1990-I. Vol. 42. N 2. P. 1470-1473.

[7] Sy H.K., Chua T.C. // Phys. Rev. B. 1993-I. Vol. 48. N 11. P. 7930-7934.

[8] Kroemer H., Nguyen C., Brar B. // J. Vacuum Sci. \& Technol. B. 1992.10 (4). P. 1769-1772.

[9] Shen J., Goronkin H., Dow J.D., Ren S.Y. // J. Appl. Phys. 1995. 77 (4). P. 1576-1581.

[10] Виноградов А.П., Дорофеенко А.В., Мерзликин А.М., Лисянский А.А. // УФН. 2010. Т. 180. № 3. С. 249-263.

[11] Vinogradov A.P., Dorofeenko A.V., Erokhin S.G., Inoue M., Lisyansky A.A. // Phys. Rev. B. 2006. Vol. 74. P. 045128.

[12] Goto T., Dorofeenko A.V., Merzlikin A.M., Baryshev A.V., Vinogradov A.P., Inoue M., Lisyansky A.A., Granovsky A.B. // Phys. Rev. Lett. 2008. Vol. 101. P. 113902(1)-113902(3).

[13] Bikbaev R.G., Vetrov S.Ya., Timofeev I.V. // J. Optics. 2017. Vol. 19. P. 015104.

[14] Kavokin A.V., Shelykh I.A., Malpuech G. // Phys. Rev. B. 2005. Vol. 72. P. 233102(1)-233102(4).

[15] Belozorov D.P., Girich A., Nedukh S.V., Moskaltsova A.N., Tarapov S.I. // Progr. Electromagn. Res. Lett. 2014. Vol. 46. P. 7-12.

[16] Anderson R.L. // Sol. Stat. Electron. 1962. Vol. 5. N 4. P. 341-351.

[17] Усанов Д.А., Скрипаль А.В., Мерданов М.К., Пономарев Д.В., Рязанов Д.С. // Физика волновых процессов и радиотехнические системы. 2015. Т. 18. № 3. Ч. 2. С. 6-19.

[18] Усанов Д.А., Никитов С.А., Скрипаль А.В., Рязанов Д.С. // Радиотехника и электроника. 2016. Т. 61. № 4. С. 321-326. 